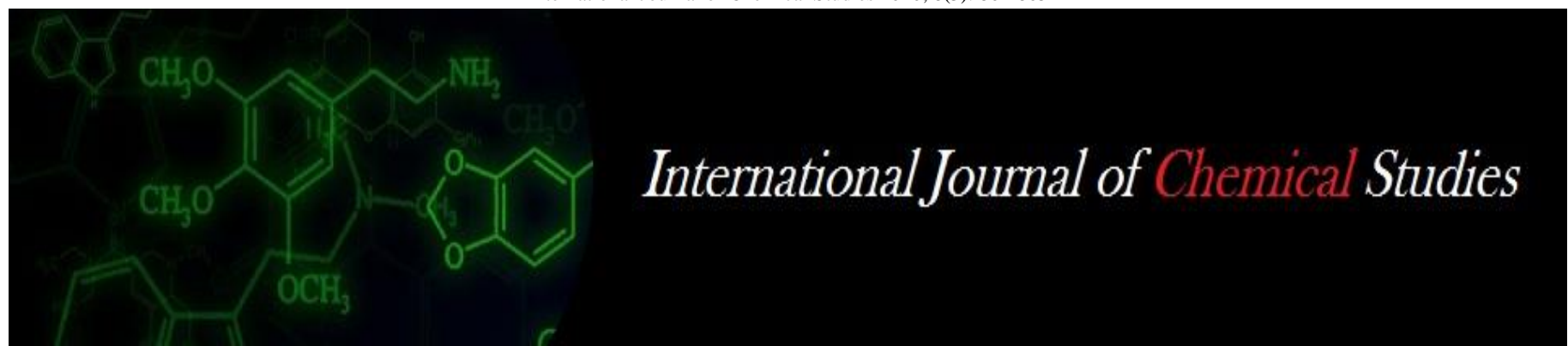

P-ISSN: 2349-8528

E-ISSN: 2321-4902

www.chemijournal.com

IJCS 2020; 8(3): 862-865

(C) 2020 IJCS

Received: 04-03-2020

Accepted: 06-04-2020

S Shailja Iyer

Department of Soil Science and Agricultural Chemistry, College of Agriculture, IGKV, Raipur,

Chhattisgarh, India

GP Ayam

Department of Soil Science and Agricultural Chemistry, College of Agriculture, IGKV, Raipur,

Chhattisgarh, India
Corresponding Author:

S Shailja Iyer

Department of Soil Science and Agricultural Chemistry, College of Agriculture, IGKV, Raipur, Chhattisgarh, India

\section{Soil fertility status of available sulfur in soil through soil fertility mapping using GPS and GIS Techniques of Dharmaur micro-watershed Jagdalpur block, Bastar District of (C.G.) State}

\section{S Shailja Iyer and GP Ayam}

DOI: $\underline{\text { https://doi.org/10.22271/chemi.2020.v8.i3k.9308 }}$

\begin{abstract}
The present study on the soil fertility status of available Sulfur in soil by soil fertility mapping using GPS and GIS techniques of the Dharmaur microwatershed Jagdalpur block, Bastar district of C.G. was conducted during 2017-18. The focus here was to prepare soil fertility mapping using GPS and GIS techniques. Sulfur is one of the important plant nutrient among 17 essential plant nutrients. It is essential for the growth and development of all crops. Without exception most of a plants requirement of $\mathrm{S}$ is absorbed through the roots in the sulphate (SO4) form. Like any essential nutrient, sulfur also has certain specific functions to perform in the plant Thus, $\mathrm{S}$ deficiencies can only be corrected by the application of $\mathrm{S}$ fertilizer. A total of 382 soil samples were collected from the area covering most of Dharmaur, Kumhrawand and Tekameta villages and the study area is surrounded by Kumhrawand village to the East, Tekameta village to the West, Indravati river to the North and Bhadisgaon \& Biringpal villages to the South.
\end{abstract}

Keywords: Soil fertility mapping, GPS, GIS

\section{Introduction}

For plant growth, sulfur is an important nutrient. In recent years the deficiency of sulfur has become increasingly recognized and the importance of sulfur in crop production has been increasingly accepted. While it is regarded as a secondary nutrient, it has become recognised as the 'fourth macronutrient' along with the use of nitrogen, phosphorus and potassium. Oil crops, legumes, forages and some vegetable crops require sulfur in considerable amounts. In certain crops the amount of phosphorus is similar in the plant. Most of the sulfur in soils is found soil in organic matter. However, it is not available to plants in this form. In order to become available to plants, the sulfur must be first released from the organic matter and go through mineralization process. The mineralization process is a result of microbial activity. In this process sulfur is converted to the sulfate form (SO4-2), which is readily available to plants. The process is affected by the $\mathrm{C} / \mathrm{S}$ ratio, temperature and moisture. Immobilization of sulfur is the opposite process in which available sulfate is converted back into the organic form. (Das 2018)

\section{Material and methods}

Study Area

Chhattisgarh state is divided into 3 Agro-climatic zones - Chattisgarh plains, Bastar Plateau, and Northern Hill zone, each covering $51 \%, 28 \%$, and $21 \%$ of the total geographical area respectively. Bastar district comes under the Bastar Plateau zone. The study area is the Dharmaur Micro-Watershed in Jagdalpur block, Bastar District of Chhattisgarh state, which is located between $19^{\circ} 2^{\prime} 30^{\prime \prime}$ to $19^{\circ} 07^{\prime} 30^{\prime \prime} \mathrm{N}$ latitude and $81^{\circ} 55^{\prime}$ to $81^{\circ} 57^{\prime} 30^{\prime \prime}$ E longitude with an altitude of ranging from 540-562 $\mathrm{m}$ above MSL. The study area covers the majority of the part of Dharmaur, Kumhrawand and Tekameta villages and is surrounded by Kumhrawand village to the East, Tekameta village to the West, Indravati River to the North, and Bhadisgaon \& Biringpal villages to the South. 


\section{District Profile}

Bastar district is situated in the southern part of Chhattisgarh state, at the height of 550 meters above mean sea level. Bastar is surrounded by Kanker to the north, Dantewada to the west, Nowrangpur to the East and Sukma to the South. The area covered by forest in Bastar is $7112 \mathrm{sq} \mathrm{km}$, which is more than $75 \%$ of the total area of the district.

\section{Agro-ecological region}

The study area falls under Garjat Hills, Dandakaranya and the Eastern Ghats, hot moist sub-humid ESR, with deep loamy red and lateritic soils, low to medium AWC and LGP 180-210 days with average annual rainfall $1295 \mathrm{~mm}$ out of which $70 \%$ rainfall occurs during June-September.

\section{Soils of Bastar}

The soil seen in the Bastar district is mainly laterite soil. Soils of red and yellow shades could also be found in patches in a few places of the district. The trap rocks occur over the slopes in the Abujhmar tract, where thin light shaded soil is seen. The beds of streams and rivers like Indravati, Godavari, and Mahanadi have fresh alluvial soil. The texture of the soil ranges from sandy to fine textured (clayed soil). The $\mathrm{pH}$ of the soil varies from 4.5 to 6.5 (slightly acidic) in Sal forest areas and 5.5 to 7.8 (slightly basic) in teak forest areas, while other forests generally tend to have intermediate values. Despite the frequent summer fires, the percentage of the organic matter in the top layer of the soil is generally quite high, varying from 0.5 to $2.5 \%$.

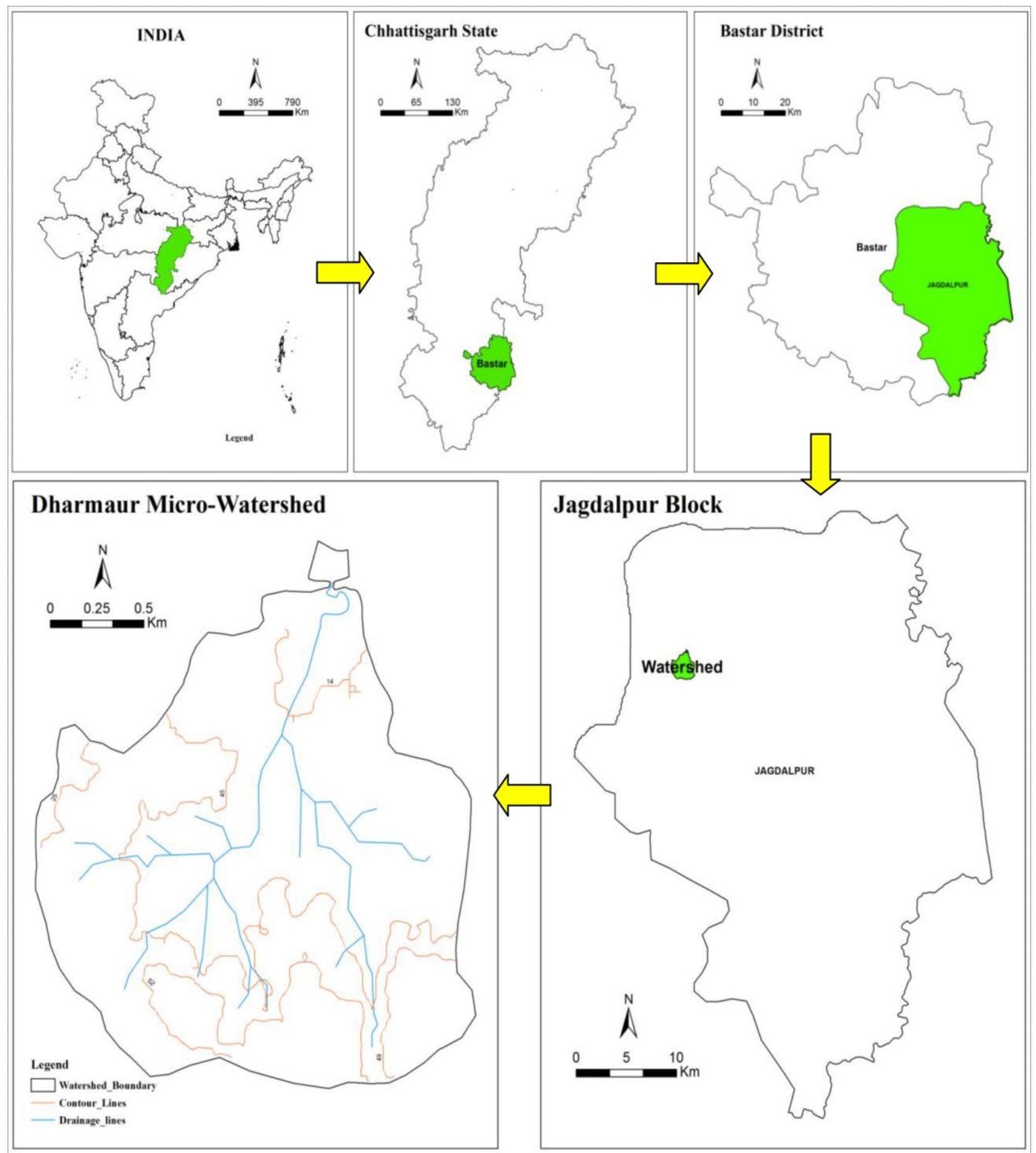

Fig 1: Location Map of the Dharmaur Micro-Watershed in Bastar district 
Estimation of available sulfur by $\mathrm{CaCl}_{2}$-Extractables (Williams and Steinbergs, 1959)

Instruments: Spectrophotometer

\section{Reagents}

1. $\mathbf{0 . 1 5 \%}$ Calcium chloride solution: Dissolve $1.5 \mathrm{~g}$ of calcium chloride dehydrate $\left(\mathrm{CaCl}_{2} .2 \mathrm{H} 2 \mathrm{O}\right)$ in $500 \mathrm{ml}$ of distilled water and make the volume to $1000 \mathrm{ml}$.

2. Barium chloride crystals: Grind $\mathrm{BaCl}_{2}$ (AR grade) crystals to pass through a 30-mesh sieve and retain on a 60-mesh sieve, and store in a clean bottle.

3. Standard S solution: Dissolve $0.5434 \mathrm{~g}$ of oven dried AR grade $\mathrm{K}_{2} \mathrm{SO}_{4}$ in distilled water and dilute to $1000 \mathrm{ml}$. This contains $100 \mathrm{ppm}$.

4. Gum acacia solution: Dissolve $0.25 \mathrm{~g}$ of gum acacia in distilled water and dilute to $100 \mathrm{ml}$.

\section{Preparation of standard Curve}

1. Take $0.25,0.5,1.0,2.5$ and $5.0 \mathrm{ml}$ of standard $\mathrm{S}$ solution in $25 \mathrm{ml}$ volumetric flask, and add $10 \mathrm{ml}$ of extracting solution (i.e. $0.15 \% \mathrm{CaCl}_{2}$ solution) to each flask. For blank, take $10 \mathrm{ml}$ of extracting solution in a $25 \mathrm{ml}$ volumetric flask.

2. Add $1 \mathrm{~g}$ of $\mathrm{BaCl}_{2}$ crystals to each flask and swirl to dissolve the crystals.

3. Add $1 \mathrm{ml}$ of of $0.25 \%$ gum acacia solution, make up the volume with distilled water and shake well manually.

4. Within 5-30 minutes of development of turbidity (white color) read the absorbance at $340 \mathrm{~nm}$ on a spectrophotometer, or on a colorimeter using blue filter.

5. Draw a curve taking $\mathrm{S}$ concentration on $\mathrm{X}$-axis and absorbance reading on $\mathrm{Y}$ axis.

\section{Procedure}

1. Weigh $10 \mathrm{~g}$ of air dry soil in a $150 \mathrm{ml}$ conical flask and add $50 \mathrm{ml} 0.15 \% \mathrm{CaCl}_{2}$ solution.
2. Shake for 30 minutes on a rotary shaker and filter through Whatman No. 42 filter paper.

3. Take $10 \mathrm{ml}$ of the clean filtrate in a $25 \mathrm{ml}$ volumetric flask, follow the steps given for standard curve to develop the turbidity and record the absorbance.

\section{Result and discussion \\ Available Sulfur}

The accessible $\mathrm{S}$ content Table 1 of Dharmaur microwatershed soils in Jagdalpur block ranged from $8.37 \mathrm{~kg} \mathrm{ha}^{-1}$ to $33.8 \mathrm{~kg} \mathrm{ha}^{-1}$ with an average value of $22.5 \mathrm{~kg} \mathrm{ha}^{-1}$. Given the soil test rating for available $S\left(<22.5 \mathrm{mgkg}^{-1}\right.$ as low, $22.5-35$ $\mathrm{mg} \mathrm{kg}^{-1}$ as medium and $>35 \mathrm{mg} \mathrm{kg}^{-1}$ as high in the status of $\mathrm{S}$ ), the available $\mathrm{S}$ content in the soils of the study area fall under low to medium status. Overall, 56.8 percent of the 382 samples fell under low status, and 43.2 percent of the samples were medium in $\mathrm{S}$ status. The low and medium amount of accessible sulfur in the study region may be due to the absence of additional sulfur, and the continued use of S-free fertilizers has resulted in crop removal of S.Status of available $\mathrm{S}$ in soils of the study area shown within the soil fertility map in Fig.2. Overall, 56.8 percent of the 382 samples fell under low status, and 43.2 percent of the samples were medium in $S$ status. Low and medium levels of accessible sulphur in the study region may be due to the absence of additional sulphur, and constant use of S-free fertilizers caused crop removal of $\mathrm{S}$. However, often the breakdown of organic matter and the mineralization process may not be fast enough to satisfy the crop's sulfur requirement, even for black soils that showed medium to elevated organic matter.

The distribution of available $\mathrm{S}$ in different farming situation in the map shows that $56.8 \%$ of soil samples of available $\mathrm{S}$ were low in Marhan, Tikra, Mal and Gabhar farming situation and $43.2 \%$ of soil samples of available $\mathrm{S}$ were medium status in Marhan, Tikra, Mal and Gabhar farming situation.

Table 1: Distribution of available Sulfur status in the soils of the study area

\begin{tabular}{|c|c|c|c|c|}
\hline Available S (kg/ha) & No.of Samples & \% Samples & Nutrient Index & Fertility Rating \\
\hline Low (<22.5) & 264 & 56.8 & \multirow{2}{*}{1.46} & \multirow{2}{*}{ Low } \\
\hline Medium(22.5-35) & 217 & 43.2 & & \\
\hline High (>35) & Nil & Nil & & \\
\hline
\end{tabular}




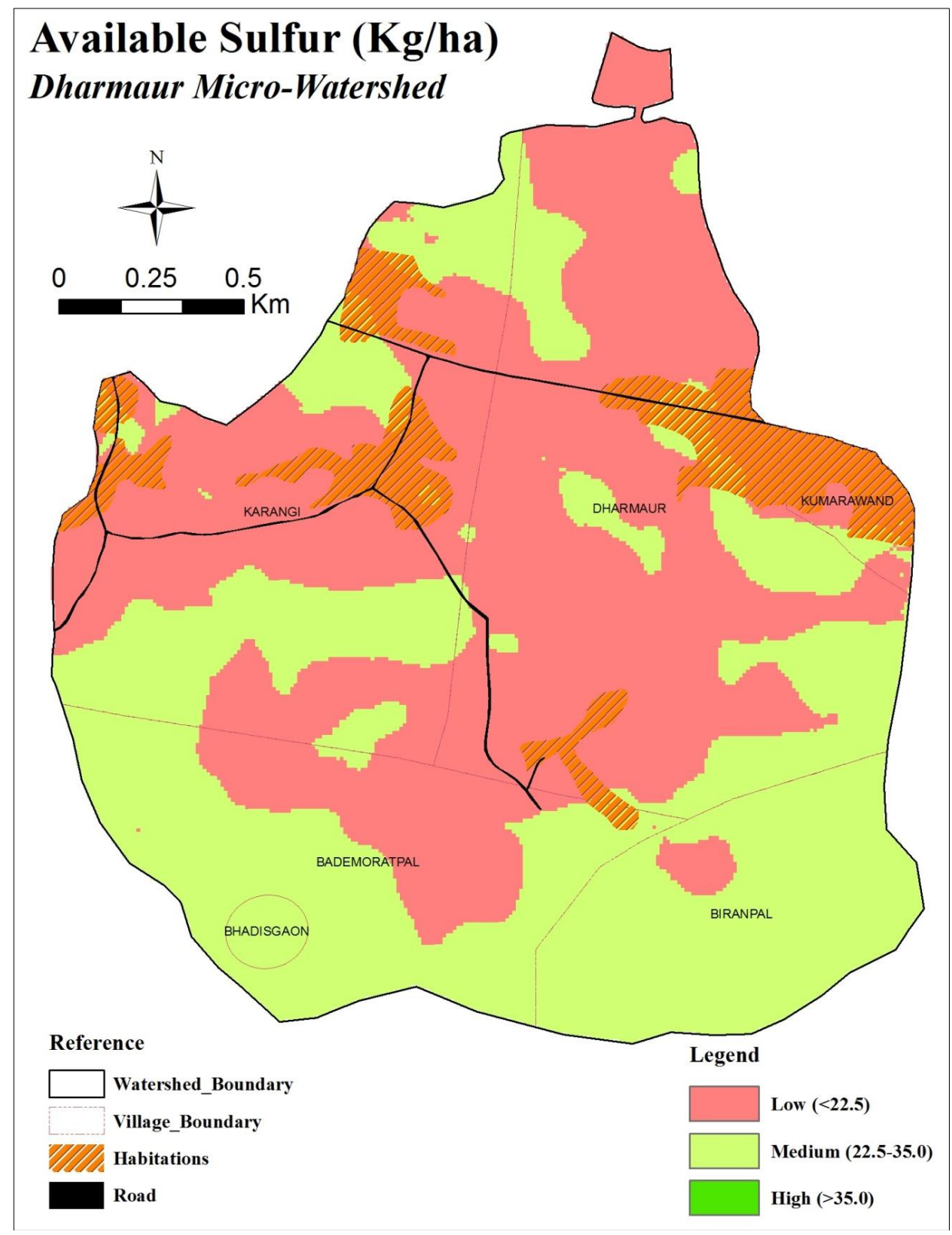

Fig 2: Status of available S in soils of Dharmaur micro-watershed

\section{Descriptive statistics analysis}

The descriptive statistics of available Sulfur are shown in Table 2 which suggested that they were all normally distributed. The science that deals with the compilation, evaluation and interpretation of numerical information (Corxton \& Cowden, 1969). This method summarizes both statistically and graphically data. It measures central of tendency of all soil parameters. The method offers a wide range of statistical data about a single variable. A logarithmic transformation is considered where the coefficient of skewness is greater than one (Webster and Oliver, 2001) ${ }^{[5]}$.

Table 2: Descriptive statistics of Available S $(0-15 \mathrm{~cm})$ depth of 382 soil Samples

\begin{tabular}{|c|c|}
\hline Descriptive Statistics & $\mathbf{S}(\mathbf{K g} / \mathbf{h a})$ \\
\hline Minimum & 8.37 \\
\hline Maximum & 33.8 \\
\hline 1st Quartile & 18.5 \\
\hline Median & 22.5 \\
\hline 3rd Quartile & 25.6 \\
\hline Mean & 22.34 \\
\hline Standard deviation & 5.65 \\
\hline Skewness & -0.03 \\
\hline
\end{tabular}

\section{References}

1. Agriculture Contingency Plan for District: Bastar by CRIDA Source: Agricultural Statistics, Commissioner land records, Raipur, Govt. of Chhattisgarh, 2009.

2. Devdas Deepika. Soil fertility mapping and tracing out limiting nutrients as production constraints for Gariyaband district of Chhattisgarh Ph.D thesis, I.G.K.V. Raipur, (Chhattisgarh), 2016.

3. Das DK. Introductory Soil Science. Kalyani Publishers, Ludhiana, 2004, 493.

4. Das. Soil fertility mapping of Nayranpur through GPS and GIS, 2016.

5. Webster R, Oliver MA. Geostatistics for Environmental Scientists. Hoboken, N.J.: John Wiley and Sons Inc, 2001. 